\title{
Facile oxygen intercalation between full layer graphene and $R u(0001)$ under ambient conditions
}

\author{
Aiyi Dong, ${ }^{1}$ Qiang Fu, ${ }^{* 1}$ Mingming Wei, ${ }^{1}$ Yun Liu, ${ }^{1}$ Yanxiao Ning, ${ }^{1}$ Fan Yang, ${ }^{1}$ \\ Hendrik Bluhm, ${ }^{2}$ XinheBao ${ }^{1}$ \\ ${ }^{1}$ State Key Laboratory of Catalysis, Dalian Institute of Chemical Physics, the Chinese \\ Academy of Sciences, Dalian 116023, P.R. China \\ ${ }^{2}$ Chemical Sciences Division, Lawrence Berkeley National Laboratory, 1 Cyclotron \\ Road, Berkeley, CA 94720, USA
}

\begin{abstract}
Graphene coatings have been widely considered as protection layers on metal surfaces to prevent surface oxidation and corrosion in gaseous atmospheres. Here, using in-situ ambient pressure X-ray photoelectron spectroscopy we demonstrate that oxygen intercalation readily occurs at full monolayer graphene/ $\mathrm{Ru}(0001)$ interfaces in 0.5 torr $\mathrm{O}_{2}$ around $150{ }^{\circ} \mathrm{C}$, resulting in decoupling of the graphene overlayer from the $\mathrm{Ru}$ surface and oxidation of the metal surface. Moreover, oxygen intercalation has been observed even upon illumination of the graphene/Ru(0001) surface with an infrared lamp in air. These results indicate that the stability of graphene/metal interfaces under ambient conditions should be taken into consideration for future applications.
\end{abstract}

Keywords: Graphene; Intercalation; AP-XPS; Oxidation; Ru(0001)

*Corresponding author. Tel.: +86-411-84379253; fax: +86-411-84694447; email: qfu@ dicp.ac.cn. 


\section{Introduction}

Graphene (Gr), a single layer of $\mathrm{sp}^{2}$-bonded carbon arranged in a honeycomb lattice, presents many outstanding physical and chemical properties [1-5]. Among them, its low chemical reactivity, impermeability to gases, and excellent mechanical strength and stiffness allow the material to be used as protection layers for metal surfaces, inhibiting surface oxidation in $\mathrm{O}_{2}$ atmosphere or corrosion in air [6-15]. It has been demonstrated that reactive metals, such as $\mathrm{Fe}, \mathrm{Ni}$, and $\mathrm{Cu}$, coated by graphene layers are resistive against oxidation or electrochemical corrosion reactions under ambient conditions $[7,9,11]$. Surface science studies confirm that $\mathrm{Gr} / \mathrm{Pt}(100), \mathrm{Gr} / \mathrm{Ru}(0001)$, and $\mathrm{Gr} / \mathrm{Rh}(111)$ surfaces remain intact when exposed to air at room temperature (RT) [13-15].

Recent experiments, however, show that many gases can intercalate under graphene flakes grown on metal surfaces [16-29]. Particularly, oxygen intercalation at the graphene/metal interfaces in $\mathrm{O}_{2}$ atmosphere and at elevated temperatures has been reported [16-19]. For example, we found that oxygen intercalation occurs at submonolayer $\mathrm{Gr} / \mathrm{Ru}(0001)$ interfaces when treating the sample in $1.6 \times 10^{-6} \mathrm{mbar} \mathrm{O}_{2}$ at $600 \mathrm{~K}$ [16]. Sutter et al. used low energy electron microscopy to monitor in-situ $\mathrm{O}_{2}$ adsorption on graphene islands and confirmed the formation of an O-adlayer at the $\mathrm{Gr} / \mathrm{Ru}(0001)$ interface [17]. A similar phenomenon was also observed by Starodub et al. and Liao et al., in which the oxygen adsorption at the $\mathrm{Gr} / \mathrm{Ru}$ interface happens in $10^{-6}$ torr range $\mathrm{O}_{2}$ and above $300{ }^{\circ} \mathrm{C}[18,19]$. Using scanning tunneling microscope (STM) and X-ray photoelectron spectroscopy (XPS), Larciprete et al. and Granas et al. demonstrated the oxygen intercalation on an extended layer of graphene on $\operatorname{Ir}(111)$ in $10^{-3} \mathrm{mbar}_{2}$ and around $500 \mathrm{~K}[20,21]$.

The contrasting results from protective coating of graphene under ambient conditions versus oxygen intercalation of graphene in ultrahigh vacuum (UHV) and at elevated temperatures raise the following questions: To which degree can graphene layers protect metal surfaces from oxidation and corrosion? Are there any temperature and pressure limits for the graphene coating effect? In the present work, taking $\mathrm{Gr} / \mathrm{Ru}(0001)$ as the model system we study $\mathrm{O}_{2}$ adsorption on the full graphene layer 
under near ambient conditions. In-situ ambient pressure XPS (AP-XPS) was applied to study the surface oxidation of $\mathrm{Ru}(0001)$ covered by a full graphene layer in 0.5 torr $\mathrm{O}_{2}$, where we observe clear evidence for oxygen intercalation and the onset of $\mathrm{Ru}$ oxidation around $150{ }^{\circ} \mathrm{C}$. Moreover, oxygen intercalation was also observed in air under an infrared lamp, which means that the interface reaction process indeed takes place in air and slightly above RT. Considering that the future graphene-based devices and materials may work in warm ambient environments, the facile oxygen intercalation at the graphene/metal interfaces may affect their performance significantly and should be taken into consideration.

\section{Experiment}

XPS and ultraviolet photoelectron spectroscopy (UPS) measurements were performed in an Omicron multiprobe UHV system, which consists of a preparation chamber, a spectroscopy chamber, and a microscopy chamber [16, 30]. In addition, a high pressure cell has been attached to the UHV system, where gases with pressure up to 4 bar can be dosed and samples be heated [31, 32]. Samples treated in this cell were transferred back to the UHV chambers for further surface science measurements without exposing them to air. XPS spectra were acquired using $\mathrm{Mg} \mathrm{K} \alpha$ ( $h v=1253.6$ $\mathrm{eV}$ ) radiation with an electron analyzer pass energy of $30 \mathrm{eV}$. UPS spectra were recorded using normal emission with $\mathrm{He} \mathrm{I}(h v=21.2 \mathrm{eV})$ and $\mathrm{He}$ II $(h v=40.8 \mathrm{eV})$ radiation. A full monolayer graphene overlayer (1 ML Gr) was obtained via exposure of the clean $\mathrm{Ru}(0001)$ surface to $5.2 \times 10^{-7} \mathrm{mbar}_{2} \mathrm{H}_{4}$ at $827{ }^{\circ} \mathrm{C}$ for $10 \mathrm{~min}$ [16]. $\mathrm{O}_{2}$ titration at $1.3 \times 10^{-6}$ mbar $\mathrm{O}_{2}$ was applied to make sure that the $\mathrm{Ru}(0001)$ surface was fully covered by the graphene overlayer. $\mathrm{O}_{2}$ intercalation on the $\mathrm{Gr} / \mathrm{Ru}(0001)$ surface under ambient condition was conducted in the high pressure cell. In addition, $\mathrm{O}$ intercalation was also attempted by putting the $1 \mathrm{ML} \mathrm{Gr} / \mathrm{Ru}(0001)$ sample in air with and without an illumination by an infrared lamp. The treated sample was then loaded back into the UHV system for subsequent XPS/UPS measurements.

AP-XPS investigations were performed at beamline 11.0.2 at the Advanced Light Source, using an ambient pressure XPS endstation described in detail in Ref. [33]. 
The full monolayer graphene on $\mathrm{Ru}(0001)$ was prepared using the same recipe as that in the Omicron system. High purity $\mathrm{O}_{2}$ was leaked into the analysis chamber through a high precision leak valve. Ru $3 \mathrm{~d}$ and $\mathrm{O}$ 1s spectra were in-situ acquired using 390 and $638 \mathrm{eV}$ photons, respectively. The Fermi edges were measured at each of the photon energies, which were used to calibrate the binding energy positions. In high pressure $\mathrm{O}_{2}$ atmosphere each measurement was carried out at a new sample position to avoid any potential beam damage.

STM images were acquired in a Createc low-temperature STM (LT-STM) system. The O-intercalated $\mathrm{Gr} / \mathrm{Ru}(0001)$ surfaces were first obtained by exposing the $1 \mathrm{ML}$ $\mathrm{Gr} / \mathrm{Ru}(0001)$ surfaces to 0.5 torr $\mathrm{O}_{2}$ at $200{ }^{\circ} \mathrm{C}$ in the high pressure cell. The samples were then taken out from the Omicron system and transferred to the Createc LT-STM system. Before imaging, the sample was annealed at $250{ }^{\circ} \mathrm{C}$ for 5 min to remove any surface contaminations during transfer in air. STM measurements were conducted at liquid nitrogen temperature in constant current mode using an electrochemically etched W tip.

\section{Results and discussions}

We started our investigations of $\mathrm{O}_{2}$ intercalation at the $1 \mathrm{ML} \mathrm{Gr} / \mathrm{Ru}(0001)$ surface using AP-XPS, and the same $\mathrm{O}_{2}$ adsorption experiments were made on a clean $\mathrm{Ru}(0001)$ for comparison (Fig. 1). It has been shown that the $\mathrm{Ru} 3 \mathrm{~d}_{5 / 2}$ peak of the clean $\mathrm{Ru}(0001)$ surface is composed of a bulk component $\left(\mathrm{Ru}_{\mathrm{B}}\right)$ at $280.10 \mathrm{eV}$ reflecting the emission from the $\mathrm{Ru}$ atoms below the first layer, and a surface component $\left(\mathrm{Ru}_{\mathrm{S}}\right)$ at $279.80 \mathrm{eV}$ originating from the top Ru layer [34, 35]. Covering $\underline{\mathrm{Ru}(0001) \text { surface by graphene may change the } \mathrm{Ru} 3 \mathrm{~d}_{5 / 2}} \underline{\text { line shape significantly due to }}$ the strong interaction of graphene carbon atoms with $\mathrm{Ru}$ surface atoms [36-38]. Nevertheless, a strong shoulder peak at the lower binding energy position compared to that of the bulk component is still present, which is attributed to the surface Ru atoms interacting strongly with graphene (noted as interface component $/ \mathrm{R}_{\mathrm{I}}$ ) $[35,38]$. Moreover, the $\mathrm{Ru} 3 \mathrm{~d}_{3 / 2}$ peaks have been overlapped with newly appearing $\mathrm{C} 1$ s peaks. The C 1s signals have been analyzed carefully, showing that two C 1s components 
with the energy separation by $0.60 \mathrm{eV}$ and relative ratio of 5:1 can be identified [29, 38]. Here, we also observed a larger C 1s component at $285.00 \mathrm{eV}$ (noted as C1) attributed to $\mathrm{C}$ atoms interacting strongly with the surface $\mathrm{Ru}$ atoms and a smaller component at $284.35 \mathrm{eV}$ (noted as $\mathrm{C} 2$ ) assigned to the non-bonding $\mathrm{C}$ atoms with the surface Ru atoms (Fig. 1(a)).

The $1 \mathrm{ML} \mathrm{Gr} / \mathrm{Ru}(0001)$ surface was exposed to 0.5 torr $\mathrm{O}_{2}$ while the sample temperature was ramped from RT to $350{ }^{\circ} \mathrm{C}$. This pressure was taken since it is close to the upper limit of the gas pressure applied in the AP-XPS endstation for in-situ experiments. Shown in Fig. 1(a) and (b) are the recorded AP-XPS Ru 3d and O 1s spectra. We can see that there is no obvious $\mathrm{O} 1 \mathrm{~s}$ signal at the temperatures of RT and $100{ }^{\circ} \mathrm{C}$. Note that the small signal at $531.1 \mathrm{eV}$ may be due to the weak functionalization of graphene by oxygen [39]. At $150{ }^{\circ} \mathrm{C}$ a strong peak at $529.9 \mathrm{eV}$ appears, which can be attributed to atomic oxygen species adsorbed on the $\mathrm{Ru}(0001)$ surface [16, 40]. In addition, a new component at $283.64 \mathrm{eV}$ appears in the $\mathrm{Ru} 3 \mathrm{~d}$ spectrum with the binding energy lower than that of the metallic $\mathrm{Ru} 3 \mathrm{~d}_{3 / 2}$ peak. When the surface was further heated to $200{ }^{\circ} \mathrm{C}$ the $\mathrm{O} 1 \mathrm{~s}$ peak intensity continues to increase, and the $283.64 \mathrm{eV}$ component becomes much stronger. The same $\mathrm{O}_{2}$ exposure onto the clean $\mathrm{Ru}(0001)$ surface already results in strong surface oxidation, forming new components at higher binding energy positions in both $\mathrm{Ru} 3 \mathrm{~d}_{5 / 2}$ and $\mathrm{Ru} 3 \mathrm{~d}_{3 / 2}$ peaks (Fig. 1(c) and(d)). Accordingly, the component appearing at $283.64 \mathrm{eV}$ on the $\mathrm{O}_{2}$-exposed $\mathrm{Gr} / \mathrm{Ru}(0001)$ surface above $150{ }^{\circ} \mathrm{C}$ should not be from any oxidized $\mathrm{Ru}$ components but can only be attributed to the $\mathrm{C}$ signal (noted as C3). Similar to our discussion about $\mathrm{CO}$-intercalated $\mathrm{Gr} / \mathrm{Ru}(0001)$ surface [29], the $\mathrm{C} 3$ component is from the graphene $\mathrm{C}$ atoms, which are decoupled from the $\mathrm{Ru}$ surface by the oxygen intercalation. Both $\mathrm{C} 1$ and $\mathrm{C} 2$ components now shift down to the same low binding energy position due to the weaker interaction of graphene with the $\mathrm{O}-\mathrm{Ru}(0001)$ surface than that between graphene and $\mathrm{Ru}(0001)$. It should be noted that the binding energy shift from $\mathrm{C} 1$ to $\mathrm{C} 3$ is as large as $-1.36 \mathrm{eV}$, which demonstrates the strong effect of the interfacial $\mathrm{O}$ intercalation on the electronic state of graphene $\mathrm{C}$ atoms. When heating the $1 \mathrm{ML} \mathrm{Gr} / \mathrm{Ru}(0001)$ surface in 0.5 torr $\mathrm{O}_{2}$ to $200{ }^{\circ} \mathrm{C}$ and eventually 
reaching to $350{ }^{\circ} \mathrm{C}$, the $\mathrm{C} 3$ component almost stays unchanged, which implies that the surface $\mathrm{C}$ atoms remain stable under the present oxidation condition.

On the basis of the comparative studies in $\mathrm{O}_{2}$ exposure of the $1 \mathrm{ML} \mathrm{Gr} / \mathrm{Ru}(0001)$ surface and the clean $\mathrm{Ru}(0001)$ surface, a few notable differences can be identified concerning the oxidation of the Ru surface with and without the graphene cover. In the low temperature regime (RT $-150{ }^{\circ} \mathrm{C}$ ), strong oxygen adsorption has been observed on the clean $\mathrm{Ru}(0001)$ surface even at $\mathrm{RT}$, in which the $\mathrm{Ru} 3 \mathrm{~d}$ surface component cannot be observed any more due to the saturation of surface Ru atoms by adsorbed oxygen atoms. However, for the $1 \mathrm{ML} \mathrm{Gr} / \mathrm{Ru}(0001)$ surface no big change was observed in the $\mathrm{Ru} 3 \mathrm{~d}$ and $\mathrm{O} 1 \mathrm{~s}$ spectra below $150{ }^{\circ} \mathrm{C}$. Only upon heating to 150 ${ }^{\circ} \mathrm{C}$ has the $\mathrm{Ru}_{\mathrm{I}}$ component been strongly attenuated. This result implies that graphene can protect the $\mathrm{Ru}$ surface from oxidation under mild oxidation conditions, for instance, 0.5 torr $\mathrm{O}_{2}$ at temperatures below $150{ }^{\circ} \mathrm{C}$ here. In the intermediate temperature regime $\left(150-300{ }^{\circ} \mathrm{C}\right)$, the ratio of $\mathrm{O} 1 \mathrm{~s}$ peak area to $\mathrm{Ru} 3 \mathrm{~d}_{5 / 2}$ peak area calculated on the two surfaces (Fig. 1(e)) shows that the amount of oxygen increases slowly on the $1 \mathrm{ML} \mathrm{Gr} / \mathrm{Ru}(0001)$ surface between 150 and $350{ }^{\circ} \mathrm{C}$, while the oxidation proceeds continuously on the clean $\mathrm{Ru}(0001)$ surface. Above $300{ }^{\circ} \mathrm{C}$, the O1s peak from the $\mathrm{O}_{2}$-exposed $\mathrm{Ru}(0001)$ surface shows an obvious broadening, and a shoulder component at $529.5 \mathrm{eV}$ appears, which is due to $\mathrm{RuO}_{2}$ (Fig. 1(b)) [40-43]. At $350{ }^{\circ} \mathrm{C}$ the bulk metallic $\mathrm{Ru} 3 \mathrm{~d}$ signal almost disappeared and the $\mathrm{Ru} 3 \mathrm{~d}_{5 / 2}$ peak is now located at $280.7 \mathrm{eV}$, which is from $\mathrm{RuO}_{2}$ phase grown on the $\mathrm{Ru}(0001)$ surface. In contrast, both $\mathrm{Ru} 3 \mathrm{~d}$ and $\mathrm{O}$ 1s spectra acquired from the $\mathrm{Gr} / \mathrm{Ru}(0001)$ surface indicate that only a small part of the surface $\mathrm{Ru}$ species have been transformed into $\mathrm{RuO}_{2}$ even at $350{ }^{\circ} \mathrm{C}$. Obviously, the quicker oxidation of Ru surface region occurs on the bare $\mathrm{Ru}(0001)$ surface than the $\mathrm{Gr} / \mathrm{Ru}(0001)$ surface.

From the O-intercalated $\mathrm{Gr} / \mathrm{Ru}(0001)$, oxygen desorption was measured by temperature-programmed heating in UHV combined with in-situ XPS measurements. The bottom curve in Fig. 2 is from the O-intercalated sample, which was prepared by heating the $1 \mathrm{ML} \mathrm{Gr} / \mathrm{Ru}(0001)$ surface in 0.5 torr $\mathrm{O}_{2}$ at $200{ }^{\circ} \mathrm{C}$ and then annealing in UHV up to $194{ }^{\circ} \mathrm{C}$. On the O-intercalated surface, the graphene layer is almost 
completely freestanding with $\mathrm{C} 1$ s binding energy at $283.64 \mathrm{eV}$ (C3). The $\mathrm{Ru} 3 \mathrm{~d}_{5 / 2}$ peak consists of the bulk Ru component at $280.1 \mathrm{eV}$ and a component due to $\mathrm{Ru}$ bonded to surface and subsurface oxygen species $\left(281.0 \mathrm{eV}, \mathrm{RuO}_{\mathrm{x}}\right)$. There is no obvious change in the spectra when heating from RT to $418{ }^{\circ} \mathrm{C}$. Above $418{ }^{\circ} \mathrm{C}$ both the $\mathrm{RuO}_{\mathrm{x}}$ and $\mathrm{C} 3$ components become weaker and, simultaneously, the intensity of the $\mathrm{Ru}_{\mathrm{B}}$ and $\mathrm{C} 1$ components increases. At $472{ }^{\circ} \mathrm{C}$ the $\mathrm{C} 3$ component has been completely converted into the $\mathrm{C} 1$ and $\mathrm{C} 2$ components. Meanwhile, the $\mathrm{RuO}_{\mathrm{x}}$ component disappears and the $\mathrm{Ru} 3 \mathrm{~d}_{5 / 2}$ peak reassumes its original shape consisting of $\mathrm{Ru}_{\mathrm{B}}$ and $\mathrm{Ru}_{\mathrm{I}}$ components. These results indicate that the graphene overlayer has gained its strong interaction with the $\mathrm{Ru}$ surface due to complete oxygen desorption. The oxygen desorption experiment also confirms that the interaction of the graphene overlayer with the Ru substrate can be reversibly tuned by intercalation/desorption of oxygen atoms at the $\mathrm{Gr} / \mathrm{Ru}$ interface.

Moreover, it is noticed that oxygen atoms desorb from the Ru surface in a facile way, i.e. between 420 and $470{ }^{\circ} \mathrm{C}$. In contrast, oxygen desorption from the O-saturated $\mathrm{Ru}(0001)$ surface necessitates an annealing temperature as high as $1000{ }^{\circ} \mathrm{C}$. The easier oxygen desorption from the $\mathrm{Gr} / \mathrm{Ru}$ interface can be attributed to the confinement effect of the graphene cover, which destabilizes adsorbates at the $\mathrm{Gr} /$ metal interfaces $[17,24,29]$. On the other hand, the possibility that oxygen removal is facilitated by the oxidation of surface $\mathrm{C}$ atoms can not be excluded [17, 20]. The top curve in Fig. 2 was taken on the fresh $1 \mathrm{ML} \mathrm{Gr} / \mathrm{Ru}(0001)$ surface. Compared to the spectrum from the surface subjected to the oxygen intercalation and oxygen desorption processes, the relative intensity of the $\mathrm{C} 1 \mathrm{~s}$ peak becomes lower, which means that a substantial part of surface $\mathrm{C}$ atoms have been etched by oxygen.

The oxygen adsorption and desorption processes were also investigated by UPS. As described above, the $1 \mathrm{ML} \mathrm{Gr} / \mathrm{Ru}(0001)$ sample was treated in the high pressure cell in 0.5 torr $\mathrm{O}_{2}$ at different temperatures and then transferred to the UHV chambers for measurements. The heating in the high pressure cell was done as follows: the temperature was first ramped to the set point value, and then the heater was switched off. At the same time, the high pressure gas was quickly introduced in the cell. Thus, 
the real temperature of the sample surface in high pressure $\mathrm{O}_{2}$ may be lower than the set point value. Fig. 3 shows the UPS He-II spectra acquired under various treatment conditions. The main feature at $9.5 \mathrm{eV}$ is characteristicfor the graphite-derived $\pi$ state $[44,45]$. Increasing the temperature to $200{ }^{\circ} \mathrm{C}$, we observed an obvious shift of the main peak to a lower binding energy position. After heating at $250{ }^{\circ} \mathrm{C}$, the peak at 7.0 $\mathrm{eV}$ becomes dominant, which is similar to the $\pi$ state of the bulk graphite surface [46, 47]. Similar to the XPS results, the UPS data confirm the decoupling of the graphene overlayer induced by the oxygen intercalation. After annealing the O-intercalated $\mathrm{Gr} / \mathrm{Ru}(0001)$ surface at $523{ }^{\circ} \mathrm{C}$ in UHV, the UPS spectrum almost resembles the line shape and line position of the clean $\mathrm{Gr} / \mathrm{Ru}$ surface, suggesting that the intercalated oxygen species have completely desorbed.

It is known that STM images of monolayer graphene grown on the $\mathrm{Ru}(0001)$ surface present a typical moiré pattern due to the strong Gr-Ru interaction and the lattice mismatch between $\mathrm{Gr}$ and $\mathrm{Ru}(0001)$ [48-52]. However, the O-intercalated $\mathrm{Gr} / \mathrm{Ru}(0001)$ surface shows much lower corrugation and the characteristic moiré patterns are no longer observed due to the structural decoupling of the graphene from the substrate surface (Fig.4(a)) [16, 17]. The atomically resolved STM image demonstrates the perfect graphene lattice (Fig. 4(b)). After annealing the O-intercalated $\mathrm{Gr} / \mathrm{Ru}(0001)$ surface in $\mathrm{UHV}$ at $523{ }^{\circ} \mathrm{C}$, the moiré patterns were recovered on the surface (Fig. 4(c)). Moreover, high resolution STM image indicates the presence of surface defects in the graphene lattice, probably due to the etching of carbon atoms by oxygen. Both UPS and STM results are consistent with the AP-XPS experiments.

Compared to the previous works which demonstrate the occurrence of oxygen intercalation in $10^{-6}$ torr range $\mathrm{O}_{2}$ and around $300{ }^{\circ} \mathrm{C}$, our present work shows that lower intercalation temperature are needed at higher $\mathrm{O}_{2}$ pressures, here 0.5 Torr. Therefore, it is expected that the oxygen intercalation may happen at even lower temperatures in higher pressure $\mathrm{O}_{2}$, such as in ambient pressure $\mathrm{O}_{2}$. To test this hypothesis, the $1 \mathrm{ML} \mathrm{Gr} / \mathrm{Ru}(0001)$ surface was illuminated by an infrared lamp in air (200 mbar $\mathrm{O}_{2}$ ), which gave a sample temperature well below $100{ }^{\circ} \mathrm{C}$. The subsequent 
XPS and UPS measurements of the illuminated surface (Fig. 5) show that a strong O 1s peak with a binding energy of $529.9 \mathrm{eV}$ appears which is attributed to atomic oxygen species absorbed on $\mathrm{Ru}(0001)$. In addition we observe a downshift of the graphite-derived $\pi$ state from 9.5 to $7.0 \mathrm{eV}$. On the basis of the above discussions, these results confirm oxygen intercalation of the graphene overlayer, resulting in decoupled graphene on $\mathrm{Ru}(0001)$. The O-intercalation process has been illustrated by Fig. 6. After annealing the O-intercalated $1 \mathrm{ML} \mathrm{Gr} / \mathrm{Ru}(0001)$ surface in UHV at 523 ${ }^{\circ} \mathrm{C}$, most of the surface oxygenspecies has been removed. At the same time, the peak at $7.1 \mathrm{eV}$ shifts back to $9.5 \mathrm{eV}$, i.e. to the position of that for the clean $\mathrm{Gr} / \mathrm{Ru}(0001)$ surface. The result indicates that the higher $\mathrm{O}_{2}$ partial pressure the lower temperature needed for the oxygen intercalation. It should be noticed that the simple exposure of the $\mathrm{Gr} / \mathrm{Ru}(0001)$ surface to air without the illumination does not produce any changes in XPS/UPS results, consistent with the previous report [14]. However, the oxygen intercalation can be activated at temperatures slightly above RT. At ambient atmosphere and close to RT, the space between the graphene cover and the $\mathrm{Ru}(0001)$ surface acts as a two-dimensional container, in which gases can be strongly confined like gas adsorption between single-layer $\mathrm{SiO}_{2}$ membrane and $\mathrm{Ru}(0001)$ [53].

\section{Conclusions}

We demonstrate that $\mathrm{O}_{2}$ can intercalate into the interface between a $1 \mathrm{ML}$ graphene overlayer on the $\mathrm{Ru}(0001)$ substrate in 0.5 torr $\mathrm{O}_{2}$ at a temperature of $150{ }^{\circ} \mathrm{C}$. The oxygen intercalation weakens the interaction between graphene and $\mathrm{Ru}(0001)$, leading to a downshift of the $\mathrm{C} 1 \mathrm{~s}$ binding energy by $-1.36 \mathrm{eV}$ and resulting in a free-standing graphene structure. The intercalated $\mathrm{O}$ atoms completely desorb from the $\mathrm{Gr} / \mathrm{Ru}$ interface below $527{ }^{\circ} \mathrm{C}$, which may be attributed to the confinement effect of the graphene cover as well as the etching of $\mathrm{C}$ atoms. The oxygen intercalation can also take place in air with the aid of an infrared lamp for illumination, showing that the Gr/metal interfaces may not be stable enough at ambient atmosphere and slightly above RT. Future graphene-based devices and materials often work in warm ambient environments, such as under direct sunshine and close to a heating source, where the 
facile oxygen intercalation at the $\mathrm{Gr} /$ metal interfaces may affect their performance and should be considered.

\section{Acknowledgments}

This work was financially supported by the National Natural Science Foundation of China (No. 21222305, No. 21373208, and No. 21033009), and Ministry of Science and Technology of China (No. 2011CB932704 and No. 2013CB834603). The ALS and the MES beamline 11.0.2 are supported by the Director, Office of Science, Office of Basic Energy Sciences, Division of Chemical Sciences, Geosciences, and Biosciences and Materials Sciences Division of the US Department of Energy at the Lawrence Berkeley National Laboratory under Contract No. DE-AC02-05CH11231. 


\section{References}

[1] A.K. Geim, K.S. Novoselov, Nat. Mater., 6 (2007) 183.

[2] A.K. Geim, Science, 324 (2009) 1530.

[3] F.N. Xia, T. Mueller, Y.M. Lin, A. Valdes-Garcia, P. Avouris, Nat. Nanotechnol., 4 (2009) 839 .

[4] C. Berger, Z. Song, X. Li, X. Wu, N. Brown, C. Naud, D. Mayou, T. Li, J. Hass, A.N. Marchenkov, E.H. Conrad, P.N. First, W.A. de Heer, Science, 312 (2006) 1191.

[5] Y.B. Zhang, Y.W. Tan, H.L. Stormer, P. Kim, Nature, 438 (2005) 201.

[6] N.T. Kirkland, T. Schiller, N. Medhekar, N. Birbilis, Corros. Sci., 56 (2012) 1.

[7] D. Kang, J.Y. Kwon, H. Cho, J.H. Sim, H.S. Hwang, C.S. Kim, Y.J. Kim, R.S. Ruoff, H.S. Shin, ACS Nano, 6 (2012) 7763.

[8] Y.S. Dedkov, M. Fonin, U. Rüdiger, C. Laubschat, Appl. Phys. Lett., 93 (2008) 022509.

[9] S.S. Chen, L. Brown, M. Levendorf, W.W. Cai, S.Y. Ju, J. Edgeworth, X.S. Li, C.W. Magnuson, A. Velamakanni, R.D. Piner, J.Y. Kang, J. Park, R.S. Ruoff, ACS Nano, 5 (2011) 1321.

[10] M. Topsakal, H. Sahin, S. Ciraci, Phys. Rev. B, 85 (2012) 155445.

[11] D. Prasai, J.C. Tuberquia, R.R. Harl, G.K. Jennings, K.I. Bolotin, ACS Nano, 6 (2012) 1102.

[12] E. Sutter, P. Albrecht, F.E. Camino, P. Sutter, Carbon, 48 (2010) 4414.

[13] L. Nilsson, M. Andersen, R. Balog, E. Laegsgaard, P. Hofmann, F. Besenbacher, B. Hammer, I. Stensgaard, L. Hornekaer, ACS Nano, 6 (2012) 10258.

[14] B. Borca, F. Calleja, J.J. Hinarejos, A.L. Vazquez de Parga, R. Miranda, J. Phys.: Condens. Matter, 21 (2009) 134002.

[15] K. Gotterbarm, W. Zhao, O. Hofert, C. Gleichweit, C. Papp, H.P. Steinruck, Phys. Chem. Chem. Phys., 15 (2013) 19625.

[16] H. Zhang, Q. Fu, Y. Cui, D.L. Tan, X.H. Bao, J. Phys. Chem. C, 113 (2009) 8296.

[17] P. Sutter, J.T. Sadowski, E.A. Sutter, J. Am. Chem. Soc., 132 (2010) 8175.

[18] E. Starodub, N.C. Bartelt, K.F. McCarty, J. Phys. Chem. C, 114 (2010) 5134.

[19] Q. Liao, H.J. Zhang, K. Wu, H.Y. Li, S.N. Bao, P. He, Appl. Surf. Sci., 257 (2010) 
82.

[20] R. Larciprete, S. Ulstrup, P. Lacovig, M. Dalmiglio, M. Bianchi, F. Mazzola, L. Hornekaer, F. Orlando, A. Baraldi, P. Hofmann, S. Lizzit, ACS Nano, 6 (2012) 9551.

[21] E. Granas, J. Knudsen, U.A. Schroder, T. Gerber, C. Busse, M.A. Arman, K. Schulte, J.N. Andersen, T. Michely, ACS Nano, 6 (2012) 9951.

[22] E. Granas, M. Andersen, M.A. Arman, T. Gerber, B. Hammer, J. Schnadt, J.N. Andersen, T. Michely, J. Knudsen, J. Phys. Chem. C, 117 (2013) 16438.

[23] Y.H. Zhang, Q. Fu, Y. Cui, R.T. Mu, L. Jin, X.H. Bao, Phys. Chem. Chem. Phys., 15 (2013) 19042.

[24] R.T. Mu, Q. Fu, L. Jin, L. Yu, G.Z. Fang, D.L. Tan, X.H. Bao, Angew. Chem. Int. Ed., 51 (2012) 4856.

[25] D.L. Ma, Y.F. Zhang, M.X. Liu, Q.Q. Ji, T. Gao, Y. Zhang, Z.F. Liu, Nano Res., 6 (2013) 671.

[26] E. Granas, M. Andersen, M.A. Arman, T. Gerber, B. Hammer, J. Schnadt, J.N. Andersen, T. Michely, J. Knudsen, J. Phys. Chem. C, 117 (2013) 16438.

[27] L.B. Gao, W.C. Ren, H.L. Xu, L. Jin, Z.X. Wang, T. Ma, L.P. Ma, Z.Y. Zhang, Q. Fu, L.M. Peng, X.H. Bao, H.M. Cheng, Nat. Commun., 3 (2012) 699.

[28] X.F. Feng, S. Maier, M. Salmeron, J. Am. Chem. Soc., 134 (2012) 5662.

[29] L. Jin, Q. Fu, A.Y. Dong, Y.X. Ning, Z.J. Wang, H. Bluhm, X.H. Bao, J. Phys. Chem. C, 118 (2014) 12391.

[30] H. Zhang, Q. Fu, Y.X. Yao, Z. Zhang, T. Ma, D.L. Tan, X.H. Bao, Langmuir, 24 (2008) 10874.

[31] Z.J. Wang, M.M. Wei, L. Jin, Y.X. Ning, L. Yu, Q. Fu, X.H. Bao, Nano Res., 6 (2013) 399 .

[32] M. Wei, Q. Fu, A. Dong, Z.-j. Wang, X. Bao, Top. Catal., 57 (2014) 890.

[33] D. Frank Ogletree, H. Bluhm, E.D. Hebenstreit, M. Salmeron, Nucl Instr.Meth.Phys. Res. A 601 (2009) 151.

[34] D.E. Starr, H. Bluhm, Surf. Sci., 608 (2013) 241.

[35] S. Lizzit, R. Larciprete, P. Lacovig, M. Dalmiglio, F. Orlando, A. Baraldi, L. Gammelgaard, L. Barreto, M. Bianchi, E. Perkins, P. Hofmann, Nano Lett., 12 (2012) 
4503.

[36] M. Vanin, J.J. Mortensen, A.K. Kelkkanen, J.M. Garcia-Lastra, K.S. Thygesen, K.W. Jacobsen, Phys. Rev. B, 81 (2010) 081408.

[37] S.M. Kozlov, F. Vines, A. Gorling, J. Phys. Chem. C, 116 (2012) 7360.

[38] A. Preobrajenski, M. Ng, A. Vinogradov, N. Mårtensson, Phys. Rev. B, 78 (2008) 073401

[39] N.A. Vinogradov, K. Schulte, M.L. Ng, A. Mikkelsen, E. Lundgren, N. Martensson, A.B. Preobrajenski, J. Phys. Chem. C, 115 (2011) 9568.

[40] R. Blume, M. Havecker, S. Zafeiratos, D. Teschner, E. Kleimenov, A. Knopgericke, R. Schlogl, A. Barinov, P. Dudin, M. Kiskinova, J. Catal., 239 (2006) 354.

[41] A. Böttcher, H. Conrad, H. Niehus, J. Chem. Phys., 112 (2000) 4779.

[42] S. Lizzit, A. Baraldi, A. Groso, K. Reuter, M. Ganduglia-Pirovano, C. Stampfl, M. Scheffler, M. Stichler, C. Keller, W. Wurth, D. Menzel, Phys. Rev. B, 63 (2001) 205419.

[43] R. Blume, H. Niehus, H. Conrad, A. Bottcher, L. Aballe, L. Gregoratti, A. Barinov, M. Kiskinova, J. Phys. Chem. B, 109 (2005) 14052.

[44] Y.S. Dedkov, A.M. Shikin, V.K. Adamchuk, S.L. Molodtsov, C. Laubschat, A. Bauer, G. Kaindl, Phys. Rev. B, 64 (2001) 035405.

[45] Y. Cui, J. Gao, L. Jin, J. Zhao, D. Tan, Q. Fu, X. Bao, Nano Res., 5 (2012) 352.

[46] A.G. Starodubov, M.A. Medvetskii, A.M. Shikin, V.K. Adamchuk, Phys. Solid State, 46 (2004) 1340.

[47] A. Nagashima, N. Tejima, C. Oshima, Phys. Rev. B, 50 (1994) 17487.

[48] T.A. Land, T. Michely, R.J. Behm, J.C. Hemminger, G. Comsa, Surf. Sci., 264 (1992) 261.

[49] M.C. Wu, Q. Xu, D.W. Goodman, J. Phys. Chem., 98 (1994) 5104.

[50] S. Marchini, S. Gunther, J. Wintterlin, Phys. Rev. B, 76 (2007) 075429.

[51] A.L.V. de Parga, F. Calleja, B. Borca, M.C.G. Passeggi, J.J. Hinarejos, F. Guinea, R. Miranda, Phys. Rev. Lett., 100 (2008) 056807.

[52] P.W. Sutter, J.I. Flege, E.A. Sutter, Nat. Mater., 7 (2008) 406. 
[53] E. Emmez, B. Yang, S. Shaikhutdinov, H.-J. Freund, J. Phys. Chem. C, 2014, doi: 10.1021/jp503253a. 


\section{Figure captions}

Fig. 1. In-situ AP-XPS Ru 3d $+C$ 1s spectra (a, c) and O 1s spectra (b, d) of the $1 \mathrm{ML}$ $\mathrm{Gr} / \mathrm{Ru}(0001)$ (a, b) and clean $\mathrm{Ru}(0001)$ (c, d) surfaces exposed to 0.5 torr $\mathrm{O}_{2}$ at various temperatures. (e) $\mathrm{O} 1 \mathrm{~s} / \mathrm{Ru} 3 \mathrm{~d}_{5 / 2}$ intensity ratios of the $1 \mathrm{ML} \mathrm{Gr} / \mathrm{Ru}(0001)$ and clean $\mathrm{Ru}(0001)$ surfaces treated in 0.5 torr $\mathrm{O}_{2}$ at the indicated temperatures.

Fig. 2. In-situ AP-XPS Ru $3 d+C$ 1s spectra acquired from the O-intercalated $1 \mathrm{ML}$ $\mathrm{Gr} / \mathrm{Ru}(0001)$ surface annealed in $\mathrm{UHV}$ at increasing temperatures from RT to $587^{\circ} \mathrm{C}$ with the heating rate of $15^{\circ} \mathrm{C} / \mathrm{min}$. Because of no change observed at low temperature range, the spectra were given between 194 and $587{ }^{\circ} \mathrm{C}$. For comparison, a spectrum of the as-prepared $1 \mathrm{ML} \mathrm{Gr} / \mathrm{Ru}(0001)$ surface was included (the top red line).

Fig. 3. He II UPS spectra of the $1 \mathrm{ML} \mathrm{Gr} / \mathrm{Ru}(0001)$ surface treated in 0.5 torr $\mathrm{O}_{2}$ at different temperatures. For comparison, a spectrum of the O-intercalation $\mathrm{Gr} / \mathrm{Ru}(0001)$ surface annealed in UHV at $523{ }^{\circ} \mathrm{C}$ was also included.

Fig. 4. LT-STM images from the O-intercalated $1 \mathrm{ML}$ Gr/Ru(0001) surface (a, $100 \mathrm{~nm}$ $\times 100 \mathrm{~nm} ; \mathrm{b}, 10 \mathrm{~nm} \times 10 \mathrm{~nm})$, and the surface annealed in UHV at $523{ }^{\circ} \mathrm{C}(\mathrm{c}, 100 \mathrm{~nm}$ $\times 100 \mathrm{~nm} ; \mathrm{d}, 10 \mathrm{~nm} \times 10 \mathrm{~nm})$.

Fig. 5. XPS O 1 s spectra (a) and He II UPS spectra (b) of the $1 \mathrm{ML}$ Gr/Ru(0001) surface illuminated by an infrared lamp in air for $5 \mathrm{~h}$. I: the as-prepared $\mathrm{Gr} / \mathrm{Ru}(0001)$ surface; II: illuminated surface, III: the surface annealed in UHV at $523{ }^{\circ} \mathrm{C}$.

Fig. 6. Schematics for $\mathrm{O}_{2}$ intercalation of $1 \mathrm{ML} \mathrm{Gr} / \mathrm{Ru}(0001)$ surface in air under an infrared lamp illumination. (a) Before illuminating the $1 \mathrm{ML} \mathrm{Gr} / \mathrm{Ru}(0001)$ surface in air; (b) after illumination for $5 \mathrm{~h}$ in air. Cyan ball: $\mathrm{Ru}$; black ball: $\mathrm{C}$; red ball: $\mathrm{O}$. 

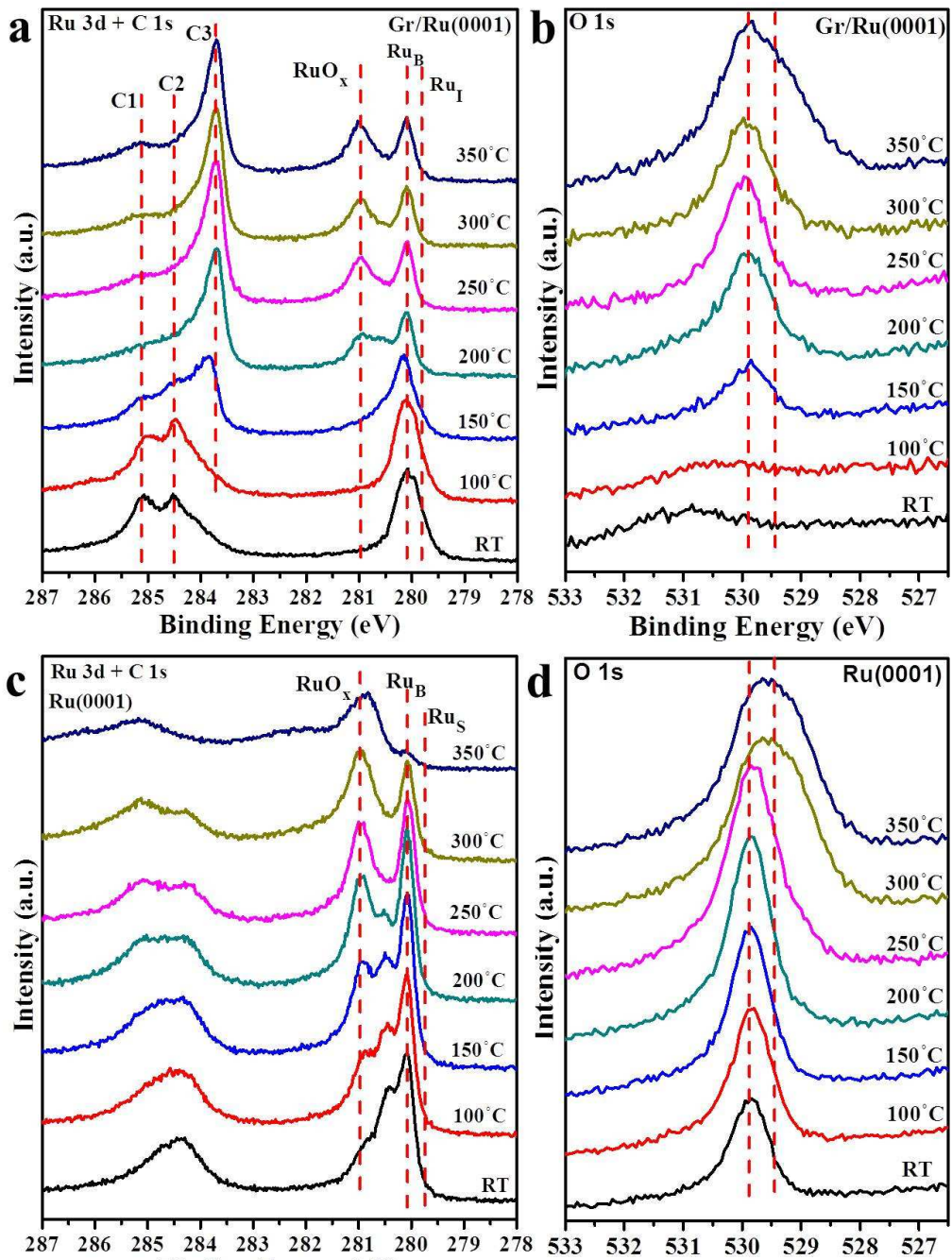

Binding Energy (eV)

Binding Energy (eV)

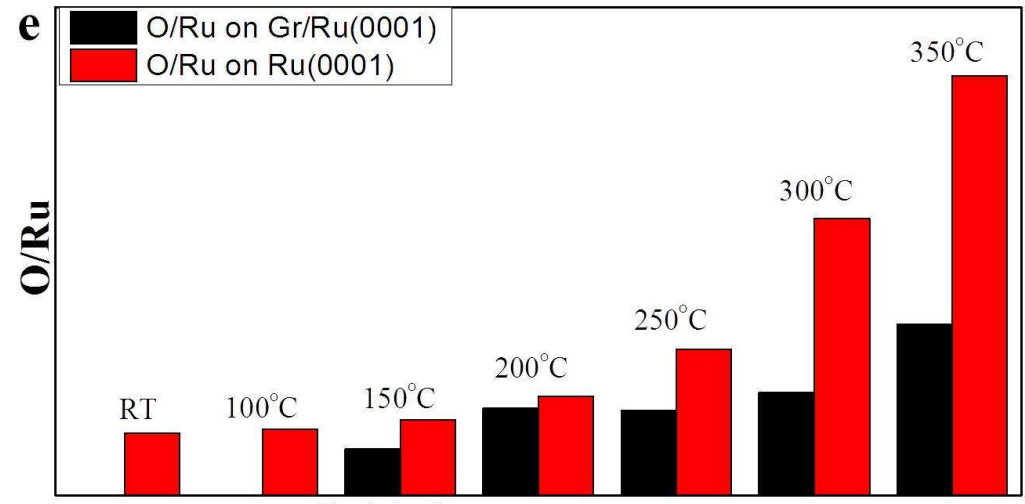

Oxidation temperature

Fig. 1. In-situ AP-XPS Ru 3d + C 1s spectra (a, c) and O 1s spectra (b, d) of the $1 \mathrm{ML}$ $\mathrm{Gr} / \mathrm{Ru}(0001)$ (a, b) and clean $\mathrm{Ru}(0001)$ (c, d) surfaces exposed to 0.5 torr $\mathrm{O}_{2}$ at various temperatures. (e) $\mathrm{O} 1 \mathrm{~s} / \mathrm{Ru} 3 \mathrm{~d}_{5 / 2}$ intensity ratios of the $1 \mathrm{ML} \mathrm{Gr} / \mathrm{Ru}(0001)$ and clean $\mathrm{Ru}(0001)$ surfaces treated in 0.5 torr $\mathrm{O}_{2}$ at the indicated temperatures. 


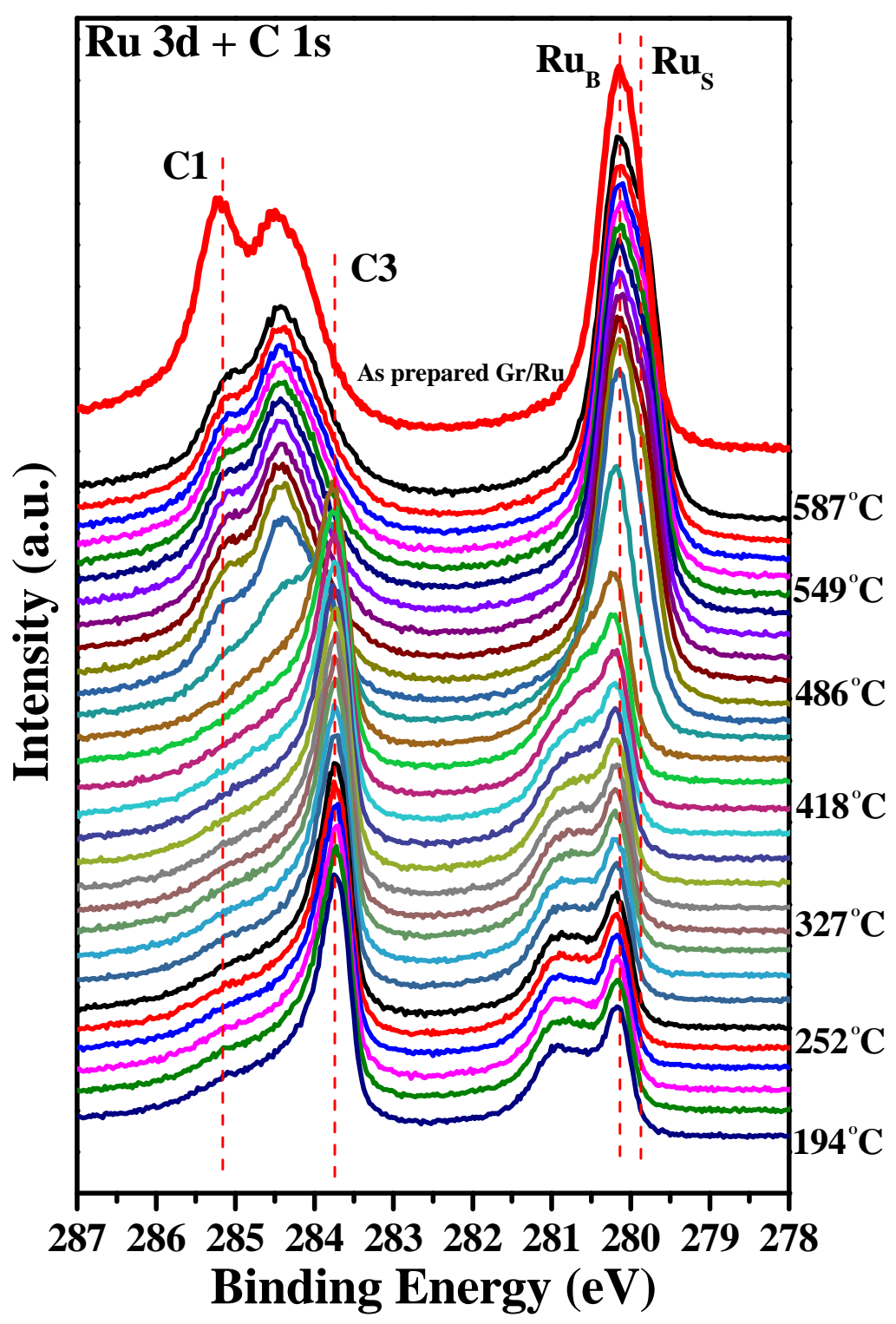

Fig. 2. In-situ AP-XPS Ru 3d + C 1s spectra acquired from the O-intercalated $1 \mathrm{ML}$ $\mathrm{Gr} / \mathrm{Ru}(0001)$ surface annealed in UHV at increasing temperatures from RT to $587^{\circ} \mathrm{C}$ with the heating rate of $15{ }^{\circ} \mathrm{C} / \mathrm{min}$. Because of no change observed at low temperature range, the spectra were given between 194 and $587{ }^{\circ} \mathrm{C}$. For comparison, a spectrum of the as-prepared $1 \mathrm{ML} \mathrm{Gr} / \mathrm{Ru}(0001)$ surface was included (the top red line). 


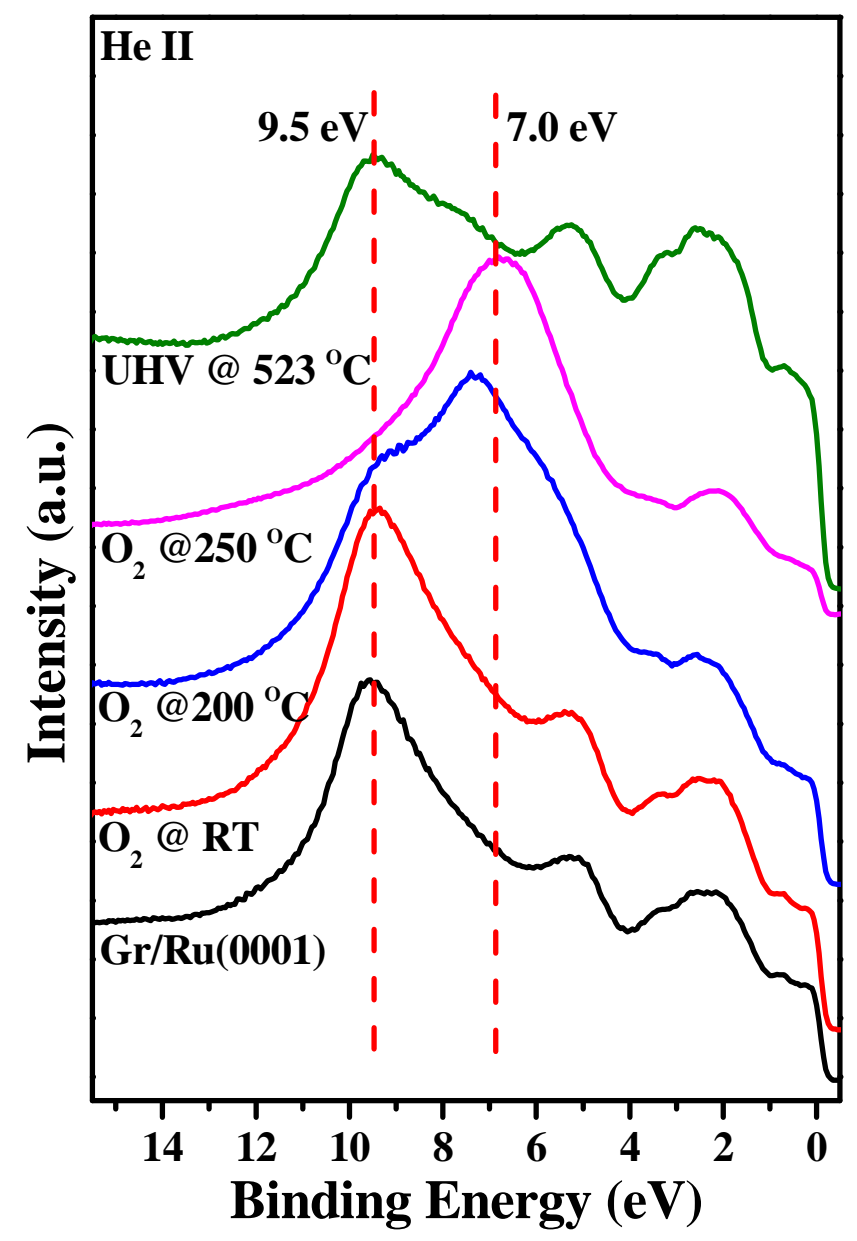

Fig. 3. He II UPS spectra of the $1 \mathrm{ML} \mathrm{Gr} / \mathrm{Ru}(0001)$ surface treated in 0.5 torr $\mathrm{O}_{2}$ at different temperatures. For comparison, a spectrum of the O-intercalation $\mathrm{Gr} / \mathrm{Ru}(0001)$ surface annealed in UHV at $523{ }^{\circ} \mathrm{C}$ was also included. 

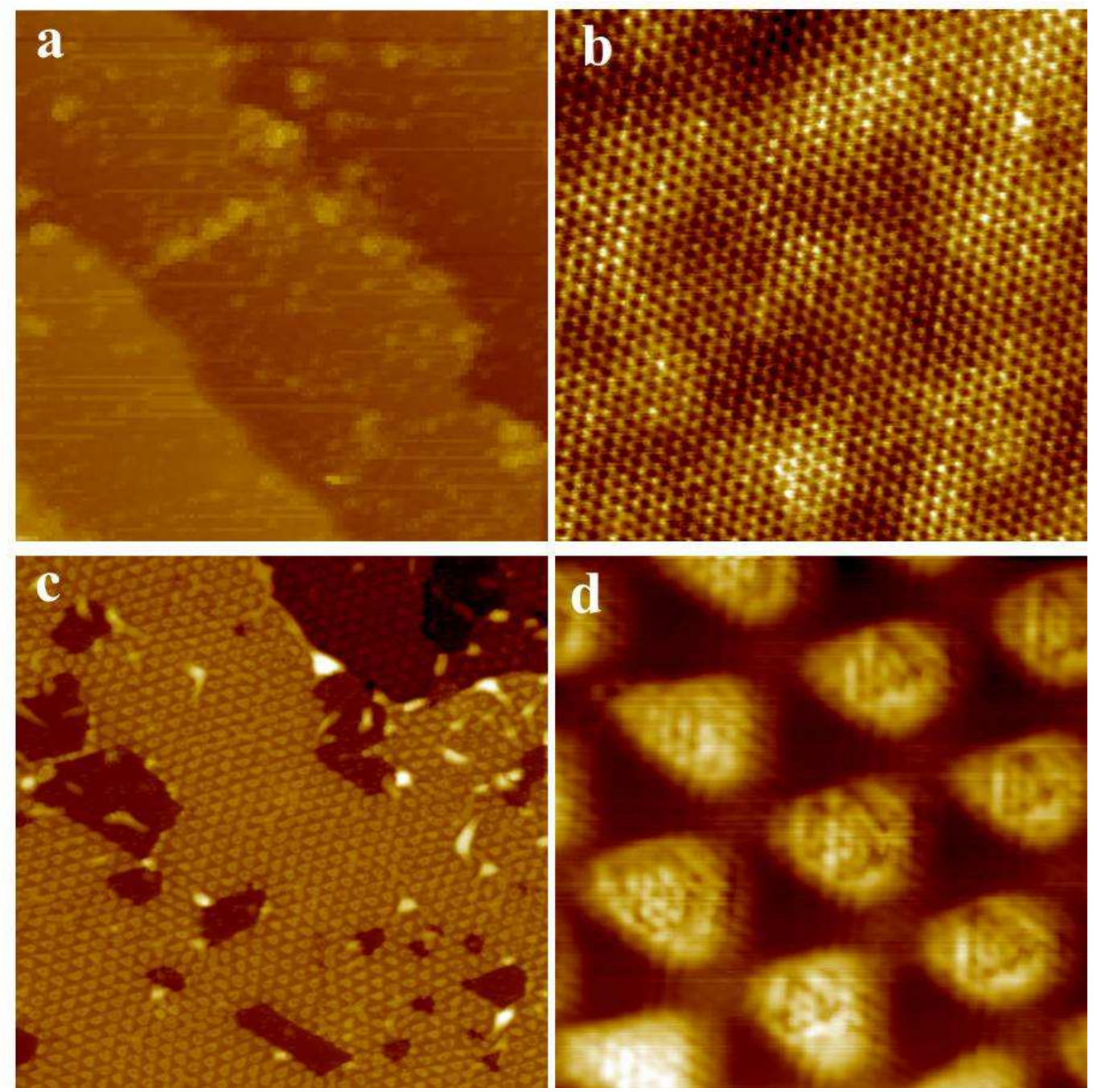

Fig. 4. LT-STM images from the O-intercalated $1 \mathrm{ML}$ Gr/Ru(0001) surface (a, $100 \mathrm{~nm}$ $\times 100 \mathrm{~nm} ; \mathrm{b}, 10 \mathrm{~nm} \times 10 \mathrm{~nm})$, and the surface annealed in UHV at $523{ }^{\circ} \mathrm{C}(\mathrm{c}, 100 \mathrm{~nm}$ $\times 100 \mathrm{~nm} ; \mathrm{d}, 10 \mathrm{~nm} \times 10 \mathrm{~nm})$. 

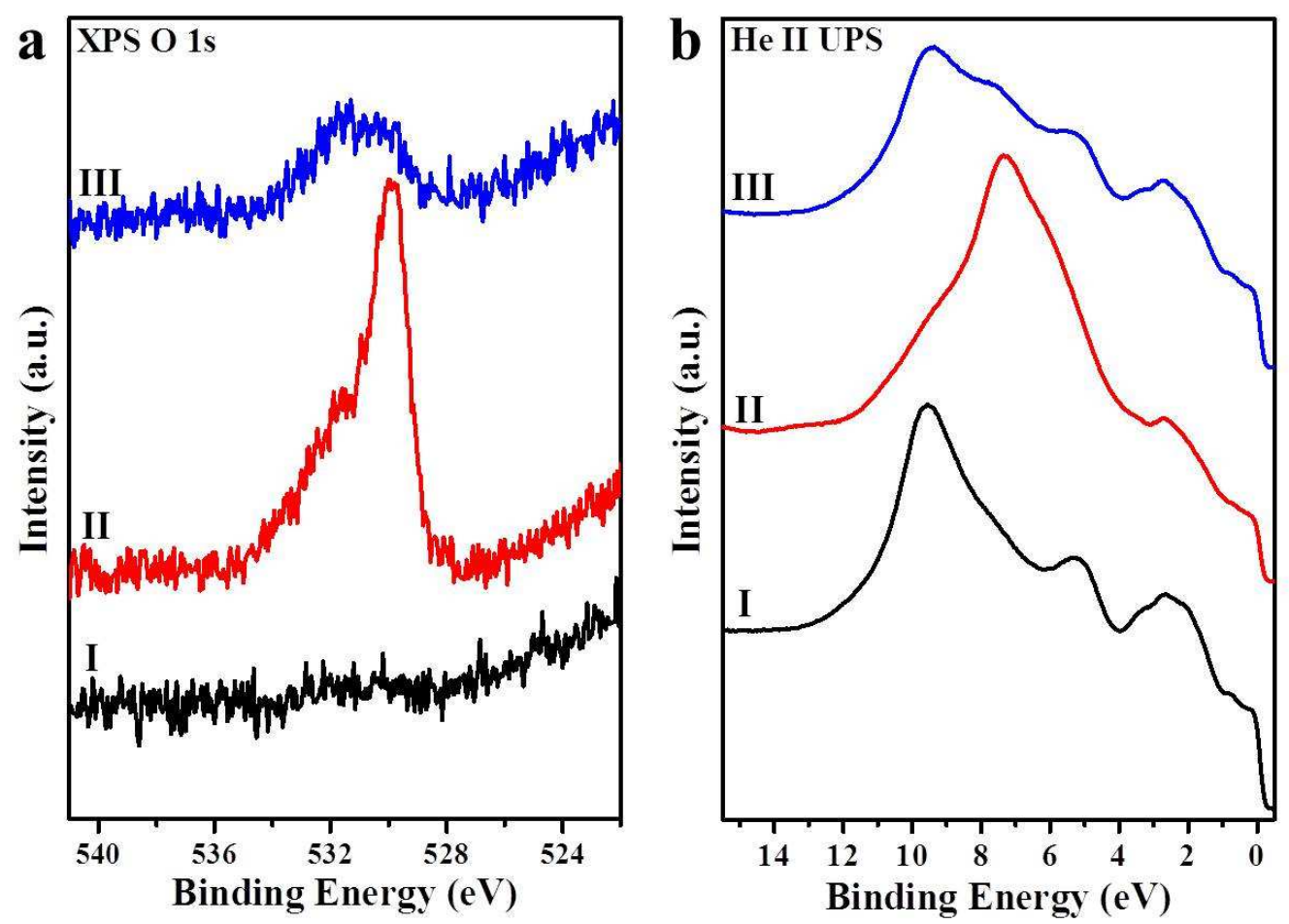

Fig. 5. XPS O 1s spectra (a) and He II UPS spectra (b) of the $1 \mathrm{ML} \mathrm{Gr} / \mathrm{Ru}(0001)$ surface illuminated by an infrared lamp in air for $5 \mathrm{~h}$. I: the as-prepared $\mathrm{Gr} / \mathrm{Ru}(0001)$ surface; II: illuminated surface, III: the surface annealed in UHV at $523{ }^{\circ} \mathrm{C}$. 


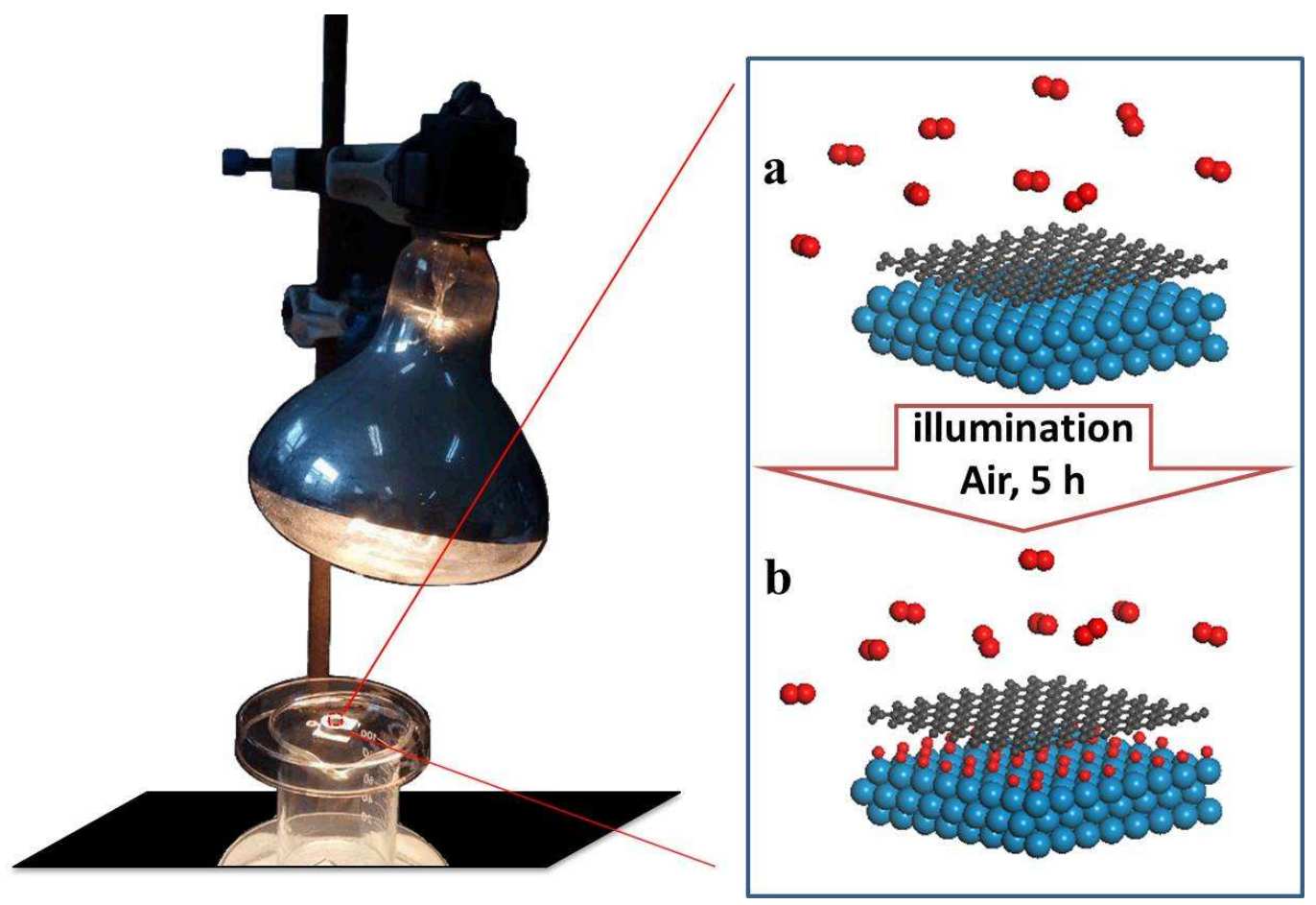

Fig. 6. Schematics for $\mathrm{O}_{2}$ intercalation of $1 \mathrm{ML} \mathrm{Gr} / \mathrm{Ru}(0001)$ surface in air under an infrared lamp illumination. (a) Before illuminating the $1 \mathrm{ML} \mathrm{Gr} / \mathrm{Ru}(0001)$ surface in air; (b) after illumination for $5 \mathrm{~h}$ in air. Cyan ball: $\mathrm{Ru}$; black ball: $\mathrm{C}$; red ball: $\mathrm{O}$. 